\title{
The clinical nurse educator as a congruent leader: A mixed method study
}

\author{
Tracey H. Coventry, Kylie P. Russell \\ School of Nursing and Midwifery, University of Notre Dame Australia, Fremantle Western Australia
}

Received: June 20, 2020

DOI: $10.5430 /$ jnep.v11n $1 \mathrm{p} 8$
Accepted: August 28, 2020

Online Published: September 10, 2020

\begin{abstract}
Educational leadership in the clinical setting has an influence on the promotion and achievement of competent and confident nurses. In Australia, the newly qualified registered nurse entering the workforce is exposed to a variety of experiential learning opportunities and engages with the nurse who is responsible for the clinical learning and development (clinical nurse educator) in the first-year graduate program. There is limited research examining the clinical nurse educator role and actual and potential leadership in the workforce. This study aimed to articulate the extent to which the clinical nurse educator is perceived as a clinical leader in the acute hospital setting. And specifically, the relationship of the role to the congruent leadership style. A mixed method convergent design (QUANT + QUAL) approach used (1) an online questionnaire with open and closed ended questions for the graduate nurses and (2) semi-structured individual interviews with graduate nurses, their clinical nurse educators and their nurse managers. Findings confirmed the clinical nurse educator leadership was visible, approachable, and relational with clearly identified values and passionate patient-centred principles. Challenges to the clinical nurse educator identity and confidence exist and impact the clinical role and leadership value. The clinical nurse educator did not need to be in a management position to lead and influence graduates' successful transition to practice and integration into the clinical environment. The clinical nurse educator exhibits a congruent leadership style through engagement and promotion of the graduate nurses in their first year of nursing. The education role is of significance to meet contemporary health care expectations and promote quality patient care and new nurse retention in the healthcare organisation.
\end{abstract}

Key Words: Clinical nurse educator, Graduate nurse, Congruent leadership, Clinical leadership, Transition to practice

\section{INTRODUCTION}

Clinical leadership is described in a variety of ways and contexts in the nursing literature. Harper ${ }^{[1]}$ identified a clinical leader as one who uses clinical expertise and communication skills to inspire others to deliver safe and quality patient care. A white paper on nurse leadership by the Australian College of Nursing ${ }^{[2]}$ indicated the clinical leader is involved in evidence-based practice, evaluating outcomes, assessing and reducing risk, and advocating for patients with a patientcentred philosophy. Sayers et al. ${ }^{[3]}$ highlight the clinical nurse educator (CNE) role as necessary for clinical leadership through providing ward clinical expertise and knowledge, and in particular facilitation of health service graduate programs to guide and progress novice nurses in their transition to competent and confident practitioners. Ashton ${ }^{[4]}$ suggested that the CNE, through educational leadership attributes has the capability to influence these newly qualified nurses and empower them for the overall benefit of optimal quality in patient care. This study explored the extent to which the CNE is perceived as a leader and their style

\footnotetext{
* Correspondence: Tracey H. Coventry; Email: tracey.coventry@nd.edu.au; Address: School of Nursing and Midwifery, University of Notre Dame Australia, Fremantle Western Australia.
} 
of leadership in a private global hospital group in Western Australia.

\subsection{Literature review}

Nursing leadership seeks to serve the healthcare organisation and clinical needs of the patient through influencing others to achieve set goals. ${ }^{[5]}$ The CNE role is necessary for hospital goals of patient-centred care led through role modelling and providing expertise and knowledge to guide and support students and newly qualified nurses in their transition to competent and safe practitioners. ${ }^{[3]}$ Practical leadership exhibited by the CNE is described in relation to skills, qualities and competence required in the role. ${ }^{[6]}$ These traits are suggested as necessary to the CNEs membership of the clinical leadership team, ${ }^{[7]}$ for resolving clinical issues and developing policies and procedures ${ }^{[8]}$ and as a mentor in developing other nurses in their personal and professional development. ${ }^{[9]}$ Furthermore, Sayers et al. ${ }^{[3]}$ found that the $\mathrm{CNE}$ in their leadership role was pivotal to integrating theory to practice in the clinical environment, as identified by the significance of the CNEs' team approach to critical thinking and clinical reasoning.

Informal bedside leadership roles such as the CNE are more overtly associated with and have significant influence on patient's safety and quality of care. ${ }^{[2]}$ Girard $^{[10]}$ illuminated the $\mathrm{CNE}$ role as a leader in an evidence-based practice example, where flexibility and responsiveness to current education needs reduce hospital-acquired complications. The CNE's leadership attributes and experience can influence a greater number of nurses through their educator role and can nurture the potential of individual nurses to empower them for the benefit of patient care. ${ }^{[4]}$ Additionally, their educational responsibilities provide structure to the ward-level leadership accountability and standards of practice. ${ }^{[11]}$

However, the contributions to literature on the CNE leadership are confined to leadership characteristics and their role in the healthcare organisations in promoting nursing workforce sustainability through education, rather than demonstration of a specific leadership style. There are several leadership styles that appear to suit the dynamic clinical environment: transformational, transactional, and authentic leadership.

Transformation leadership, a relational leadership style encourages a connection between leader and follower, with the foundation of this relationship a shared vision providing meaning and direction. ${ }^{[12]}$ Transactional leadership, is a task focused leadership style which encompasses goal setting, gives direction, and uses rewards to be successful in the clinical environment. ${ }^{[13]}$ Authentic leadership, differs in practice by emphasising the leader's ability to have insight into their own, and others' beliefs, values and strengths for the benefit of the team. ${ }^{[14]}$ However, these leadership styles are more frequently cited for nurse executives and managers rather than the nurse with a clinical focus.

The congruent leadership style was proposed by Stanley ${ }^{[15]}$ to explain and understand leadership as enacted in the clinical arena by clinically focused staff in all healthcare-related disciplines. Stanley ${ }^{[16]}$ found that the prominent leadership style of the time, transformational leadership, was inadequate to explain the type of leadership displayed by leaders in a clinical context. In his studies, Stanley ${ }^{[17]}$ identified the key features of congruent leadership as motivation, inspiration, approachability, visibility, actions based on values and beliefs, effective communicator, empowered, guided by passion and compassion and builds enduring relationships, without the need to have a title or hierarchical position.

In a review of the literature on the CNE role in relation to the current Australian healthcare policy, Stanley ${ }^{[18]}$ suggested that the clinical leader does not need to be in a management position to lead and influence colleagues. Sayers et al.[3] view the CNE as the most appropriate clinical role to provide leadership to bedside nurses. However, despite this support of the CNE role and their actual and potential leadership, there is limited research examining the CNE's leadership role in the real world of continual change, consumer expectations and healthcare bureaucracy.

\section{Methodology}

\subsection{Research design}

The study employed a mixed methods approach to articulate the clinical leadership of the CNE. The Convergent design (QUANT + QUAL) was chosen as the best fit to address the research aim and questions, and as being best suited to the timing and priority of the data collection and analysis. ${ }^{[19]}$ The Graduate Registered Nurses (GRN) in their first year of nursing were the lens through which the CNE clinical leadership was evaluated in the context of their patient safety and quality of care. In utilising a convergent design, a picture of the CNE leadership was formed from three different perspectives: the GRN, CNE and Clinical Nurse Manager (CNM). The quantitative and qualitative data were collected concurrently; an online questionnaire with open and closed ended questions and face to face interviews. This approach provided a greater insight into the CNE leadership in relation to their role in the clinical setting. The data was merged after separate analysis with further comparisons during the interpretation stage ${ }^{[19]}$ For this paper, only the results pertaining to the CNE leadership are reported here. 


\subsection{Site and Sample}

This study was conducted in a private global hospital group in Western Australia. Three hospital sites were included of which two were private/public acute care hospitals and one a private acute care hospital. The GRN, CNE and CNM population for this study were both full-time and part-time employees at the three hospitals. The convenience sample for the online questionnaire was the accessible GRN population who were currently in or had completed their first year of nursing in a nursing graduate program between 2012 and 2015. The simplified formula for proportions by Yamane ${ }^{[20]}$ was used to determine sample size. The GRN population for the online questionnaire was 122 . The confidence interval was determined at $95 \%$ and the degree of variability was assumed maximum variation $(p=0.5)$, and sampling error determined as 0.13 .

The interview phase used purposeful sampling as the strategy that provided the richest source of information through subgroup selection. ${ }^{[21]}$ The purposive samples were the newly qualified GRNs, the CNEs who facilitated or supervised the graduate learning of the GRNs in the clinical environment as part of the nursing graduate programme and the CNM of areas where GRNs were allocated. Using this multilevel sampling relationship, the three subgroup samples were chosen to provide the richest source of information and to obtain understanding of and insight to the role of the CNE. ${ }^{[21]}$ The qualitative sample size in this study was guided by the saturation of the data. ${ }^{[22]}$

\subsection{Data Collection}

The quantitative data were collected through the online questionnaire which consisted of questions related to information and consent (1), demographic information (5), CNE role (17), clinical leadership (10), and one final comment. The questionnaire was developed by the researcher in consultation with six professional and clinical experts to provide a forum for the GRNs' open and honest responses on the CNE role and leadership. ${ }^{[23]}$ In addition, the questionnaire incorporated qualities and characteristics associated with clinical leadership from the existing Perceptions of Clinical Leadership Questionnaire, two of which contained 54 qualities or characteristics to determine the 'most' and 'least' characteristics associated with clinical leadership, and one question regarding other qualities or characteristics identified with clinical leadership not on the list. ${ }^{[15,18]}$ The questionnaire was used with permission from the author. The response options for the items reported here included a five-point Likert scale, multiple-choice and text entry questions. A cognitive pilot formed the final phase of questionnaire by three graduate nurses, two clinical staff educators and two faculty supervisors to check quality and face validity. ${ }^{[24]}$

Participants were identified from the education and human resources departments shared database of hospital-assigned email addresses. The study information and link to the questionnaire was emailed to the GRNs by a third party with a reminder sent at two and four months from the commencement of the data collection. Recruitment of GRNs for the voluntary interviews occurred when participants responded to the invitation to contact the researcher at the end of the anonymous questionnaire. The CNEs and CNMs were invited to an interview by email.

The purpose of the semi-structured interview was to explore the GRNs $(n=10)$, CNEs $(n=11)$ and CNMs $(n=9)$ views and experiences of the $\mathrm{CNE}$ role and leadership in the clinical environment. A topic guide with questions derived from literature on the CNE role, identity, responsibilities and expected behaviours was developed. In addition, questions pursued the participants' views on the CNEs' leadership in the clinical area and contemporary culture in the hospitals. The same topic guide was used for the GRN, CNE and CNM subgroups. The researcher interviewed nurses from each subgroup until saturation occurred.

\subsection{Data Analysis}

The quantitative data was analysed using descriptive statistics. Qualtrics was used for the questionnaire, ${ }^{[25]}$ with the results summarised in statements and figures. The interview demographic data was entered into a Microsoft Excel spreadsheet and statistics generated and displayed in tables. The qualitative data from the open-ended questions and interviews were organised using coding and categorising aided by NVivo $10^{[26]}$ and followed Braun and Clarke's ${ }^{[27]}$ step by step guide to thematic analysis. The steps included becoming familiar with GRN, CNE and CNM interview transcripts, searching for patterns and differences, reviewing initial categories with continuous iteration to refine and name themes and producing a final report with examples from the raw data to provide a rich description. Trustworthiness was reflected in the use of the following strategies: ${ }^{[22]}$ Participant member checking as a quality process to verify the accuracy and authenticity of the transcription, researcher and faculty supervisors independent review of transcripts and subsequent themes for congruence, and a record of the research steps and decisions on the management, analysis and reporting of data to support the accuracy of findings.

\subsection{Ethical Considerations}

This research demonstrated the principles of honesty, integrity, respect and ethical behaviour through safe and secure practices guided by the National Statement on Ethical Con- 
duct in Human Research. ${ }^{[28]}$ University (ECU11766) and hospital (JHC1436/HPH400) ethical clearance was granted for this study. Consent was given voluntary following the provision of information on the study. All participants were protected by anonymity with interviewees coded to minimise identification potential in data. ${ }^{[22]}$

\section{Results}

\subsection{Quantitative data}

The online questionnaire response rate (RR) was 33\% (n =40), and was considered low. However, Cooper and Brown ${ }^{[29]}$ acknowledge that RRs for online questionnaires from health care professionals are often lower due to a lack of time, perceived value, and concerns about anonymity, with paper questionnaires eliciting higher RRs. The RR was considered acceptable by the researcher, biostatistician and faculty supervisors to meet the research interest in the GRNs' perspectives on the role of the $\mathrm{CNE}$ in relation to their first year of nursing.

\subsubsection{Demographic profiles}

Of the GRN questionnaire participants $(n=40)$ over half were between 21 and 30 years $(51 \%)$ and a quarter between 41 and 50 years (28\%). All GRN interview participants were female, worked an average of 66 hours per fortnight in rehabilitation, mental health, emergency, medical and surgical wards. The highest level of postgraduate education was a Graduate Certificate. Most participants (77\%) completed their GRN program in the largest of the three hospitals participating. The GRN, CNE and CNM interview participant's demographic profiles are presented in Table 1.

Table 1. GRN, CNE and CNM Interview Characteristics

\begin{tabular}{|c|c|c|c|c|c|c|}
\hline \multirow{2}{*}{$\begin{array}{l}\text { Interview Profile } \\
\text { Variable }\end{array}$} & \multicolumn{2}{|c|}{ GRN } & \multicolumn{2}{|l|}{$\mathrm{CNE}$} & \multicolumn{2}{|c|}{ CNM } \\
\hline & $\mathbf{n}$ & $\%$ & $\mathbf{n}$ & $\%$ & $\mathbf{n}$ & $\%$ \\
\hline Sex (female/male) & $10 / 0$ & 100 & $11 / 0$ & 100 & $7 / 2$ & $78 / 22$ \\
\hline \multicolumn{7}{|l|}{ Length of time as $R N$} \\
\hline$<1$ year & 7 & 70 & & & & \\
\hline $1-2$ years & 1 & 10 & & & & \\
\hline$>2$ years & 2 & 20 & & & & \\
\hline 5-10 years & & & 1 & 9.1 & 0 & 0 \\
\hline $10-20$ years & & & 4 & 36.4 & 4 & 44.5 \\
\hline$>20$ years & & & 6 & 54.5 & 5 & 55.5 \\
\hline \multicolumn{7}{|c|}{ Length of time in current role } \\
\hline$<2$ years & & & 2 & 18.2 & 2 & 22.2 \\
\hline $2-5$ years & & & 8 & 72.7 & 2 & 22.2 \\
\hline$>5$ years & & & 1 & 9.1 & 5 & 55.6 \\
\hline \multicolumn{7}{|c|}{ Highest level of postgraduate education } \\
\hline Master Degree & & & 2 & 18.2 & & \\
\hline Graduate Diploma & & & 3 & 27.2 & & \\
\hline Graduate Certificate & 8 & 80 & 2 & 18.2 & 2 & 22.2 \\
\hline None & 2 & 20 & 4 & 36.4 & 7 & 77.8 \\
\hline
\end{tabular}

\subsubsection{Questionnaire}

The Perceptions of Clinical Leadership Questionnaire ${ }^{[30]}$ contained a list of 54 qualities and characteristics that were ranked in order of preference. The GRNs were asked to select the attributes that they strongly and least associated with the CNEs clinical leadership role. The top eight ranked attributes of strongly associated and least associated with CNE clinical leadership are highlighted in Table 2.

The GRNs suggested the additional qualities or characteristics identified with the CNEs clinical leadership not on the list were organised, realistic, and patient. The majority of GRNs $(94 \%, \mathrm{n}=30)$ agreed or strongly agreed that they believed the CNE needed to have leadership qualities as part of their role to be able to help nurses give safe and quality patient care. The GRNs also indicated the degree to which they believed the CNE, shared their values, beliefs, and principles; encouraged positive cultural change in the ward; promoted themselves as a leader in the ward; were guided by concern and compassion and had an influential leadership role in the ward and in the hospital. Figure 1 outlines the results. 
Table 2. CNE Attributes Strongly and Least Associated with Clinical Leadership

\begin{tabular}{llll}
\hline Rank & Strongly Associated with Clinical Leadership & Participant Numbers & \% \\
\hline 1 & Is approachable & 29 & 72.5 \\
2 & Is supportive & 28 & 70.0 \\
3 & Is clinically competent & 26 & 65.0 \\
4 & Sets direction & 25 & 62.5 \\
4 & Sets goals and targets & 25 & 62.5 \\
4 & Is a mentor & 25 & 62.5 \\
4 & Is caring/compassionate & 25 & 60.0 \\
5 & Has integrity and honesty & 24 & $\mathbf{\%}$ \\
\hline Rank & Least Associated with Clinical Leadership & Participant Numbers \\
\hline 1 & Is controlling & 22 & 55.0 \\
2 & Works alone & 19 & 47.5 \\
3 & Takes calculated risks & 15 & 37.5 \\
4 & Is an administrator & 12 & 30.0 \\
4 & Is artistic/imaginative & 12 & 30.0 \\
5 & Deals with reward/punishment & 12 & 30.0 \\
\hline
\end{tabular}

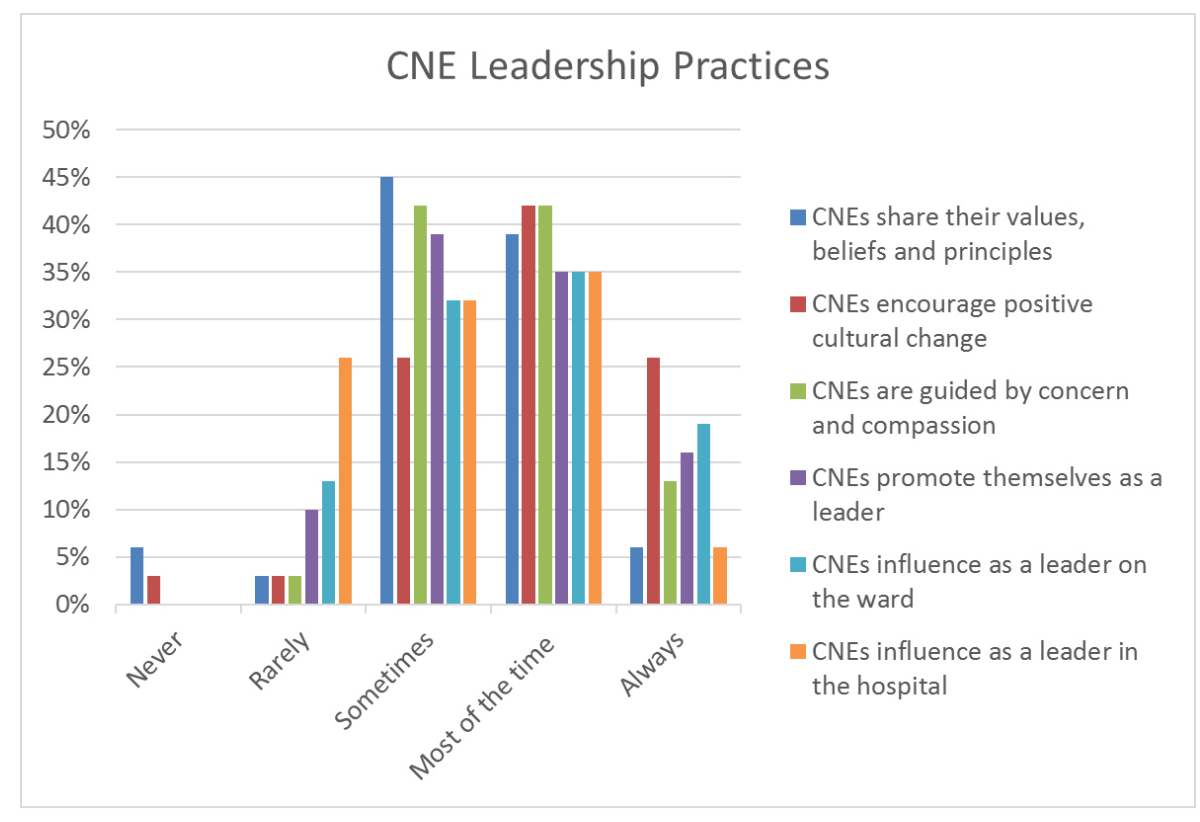

Figure 1. Results of CNE leadership questions

\subsection{Qualitative data}

The key concepts of the GRN, CNE and CNM participant perspectives on the CNE clinical leadership were derived from the interview data and highlighted the affirmative and less desirable aspects of the role (see Figure 2).

\subsubsection{GRN Perspectives}

\section{1) Influential presence}

The GRNs recognised their need for significant support to help them transition from novices to competent and confident practitioners. One GRN reflected on this role: 'Someone there to provide that extra support when needed in that first year of your nursing career and to help you transition from being a student into a professional in a busy working environment'.

The GRN participants defined the qualities of the CNE lead- 
ership: 'They're a leader of good examples and best practice, and role modelling and friendliness' and 'It takes a certain person ... they've got to be interactive with people as well as they have to be great at the theory side of it but ... patient and all that sort of thing'. The GRN participants identified the $\mathrm{CNE}$ as a genuine presence and influence on their career progression. The CNE was recognised as leader in the ward team - the trusted nurse who provided the tangible sponsorship to advance their practice: 'They provide you direction and guidance in your learning journey ... and goals to achieve. They need to be a fairly strong person to provide that direction, but not overpowering or anything'.

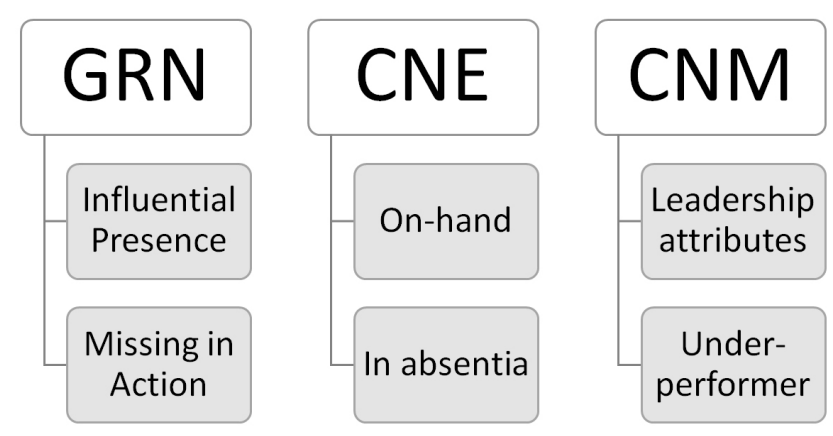

Figure 2. Concept map of the participant perspectives on the $\mathrm{CNE}$ role

The CNE's genuine offer to help resulted in spontaneous time devoted to the GRNs' progress. To the GRNs, this was identified as a characteristic of the CNE's leadership skillset, where the intent of the CNE was to guide the GRNs to the successful completion of the graduate programme. The GRN participants expressed how the CNE status enhanced the ability to guide: 'There is someone who is not managing their own patients that can give their opinion on your patients without compromising their own patients' time'. Another characteristic of CNE leadership identified by the participants was clinical expertise. One GRN expressed: 'When the CNE is available, she is a wealth of knowledge'. Another GRN participant explained: 'When I was a grad I always thought, well, the most qualified person to ask is the CNE, so even simple questions, ... I'd better ask my CNE'.

\section{2) Missing in action}

Conversely, the GRNs observed that the CNEs generally worked during business hours and that the majority of CNEs worked part-time hours. Further, the GRNs commented on how the initial time spent with them during orientation gradually reduced: 'It's really good when you first start off to have a few supernumerary days with her. It would be nice to see more of her'. The GRNs experienced times when they were expected to complete a task or skill without the knowledge

Published by Sciedu Press or competence required. With the absence of the CNE, the GRNs turned to their team members, yet often found them unable to devote them time due to their own workload. This lack of opportunity to gain skills and give holistic care was a source of ongoing frustration. One GRN commented: 'I was unable to perform tasks for example; IDC [indwelling catheter] insertion, NGT [nasogastric tube] insertion as I needed supervision for my first attempt and the ward was too busy for the shift coordinator to supervise me. Instead a colleague had to do it whilst I assisted with her tasks'.

The GRN participants discussed how the absence of the CNE affected their nursing care. This included the effect of the lack of supervision: 'I don't think it impacted on my patient care, however I feel at many times GRNs are just put on the ward and left to their own devices and I feel expected to know'. The GRNs had an expectation that the CNE role incorporated leadership through direction and guidance during their first year. One GRN participant described the first ward allocation as the time where the CNE was essential: 'They are very needed, because it was very difficult the first six months, not having that sort of support all the time'. Another GRN condensed the disappointment of not having an accessible CNE into one sentence: 'I feel in many respects that I have been alone on my GRN journey through limited availability of the CNE or the ward being busy'.

The GRNs' view of the CNE's leadership characteristics was based on their successful progress through the graduate programme, during which the absence of CNE guidance and direction created obstacles for completing the graduate programme educational requirements. One GRN summarised this view: 'They're a huge influence. What they're teaching you is what you carry on through the rest of your career'.

\subsubsection{CNE Perspectives}

\section{1) On-hand}

The CNE participants perceived their role as a position of responsibility: 'All of our function is leadership and actions. You have to lead by example and show the way and develop, educate, be an advocate for the patients and the staff'. In particular, the CNEs believed that they demonstrated clinical leadership through being on-hand and supervising the new GRNs' practice: 'We're leaders of education, we're leaders of change, to make the patient's experience better, we're here for patient outcomes'.

The CNEs highlighted ways in which they influenced the GRNs' practice though their role characteristics. These characteristics included educator, role model, clinical expert and advisor. One CNE articulated how her role was instrumental in the development of the new GRN: 'I think the leadership is what pulls the grads along, because they feel that's what 
they want to aspire to'. To be a successful CNE, participants noted that visibility in leadership was paramount: 'To provide a good role, or to fulfil your role, you need to be seen'. The CNE participants noted that their educational leadership role with the GRNs included setting a positive example as follows: 'I have to lead ... really by example'. Another participant elaborated: 'Like, I don't walk past a bell. I don't leave someone on the toilet ... If someone needs help on the other side, I would go over and see what needs doing'.

The CNE leadership encompassed a degree of expert clinical knowledge and skill. In this example, the CNE's communication of evidence-based practice was evident: 'There was one of our grads with a student who was going to take out a drain. And I heard some incorrect procedure, so I just pulled her aside and said, 'You know, our policy is changing all the time, so before you give anything to a student ... to do, always read the policy yourself. So go and print it off and have a read and, you know, we clamp our drains now, we don't disconnect them'.

The CNEs described how their role as advisor informed the staff opinion of the CNE as a leader: 'They see people coming to me asking me questions all the time. They can see information that's been put out by me or perhaps seeing the role that the CNE takes in ward meetings'. Another participant elaborated on the respect gained from this advisory role: 'Like allied health and the doctors, slowly they start to look to you for things, and that again builds up that respect and other people notice and then see you as a leader'.

\section{2) In absentia}

When the CNEs were not present, there were support gaps evident for the GRNs. One CNE participant shared an experience with GRNs and team members after an absence: 'When I wasn't on the ward for a period of time, it was definitely noticed and mentioned by all my grads on my return. Mainly not only for support for them ... as well as my staff members, which in turn helps their teamwork'.

The CNE participants described the new GRNs' need for assistance in working through and understanding what could sometimes be perceived as 'the overwhelming amount [of] documentation' required for each patient care episode. One participant shared her experience: 'I had a recent bereavement and I was away for three weeks, and when I got back all three of the grads said, 'I'm so glad you're here ... I've got so much paperwork; I don't know what I'm doing'. Also working on competencies required extra time and patience. These practice moments were difficult for ward staff to include in their busy shift times. Another participant highlighted this lack of practice: 'When you only do part time work or you've had a day off sick ... the poor girl didn't end up doing any medication practice because nobody wants to take the time to then have a third person checking'.

Being available to the GRNs was important to the CNE participants. However, when they were confronted with the results of their absence, it created frustration: 'Because I was doing set days ... I could go without seeing one of my grads for a week. It was awful. I hated it, and I felt like I wasn't achieving my goal, and my role, by not supporting him'. Conversely, the CNEs' absence created added stress for the GRNs: 'So if you're not there, and their team member happens to be busy with another sick child and they [the GRN] are then left to sort of look after the rest, it is very, very stressful for them'.

In the absence of the CNE, support gaps were evident and affected the GRNs' progress. One CNE participant provided an insightful comment on the outcomes of their leadership: 'That's what we do because at the end of the day I would like to be in the hospital bed and know that they're well trained'.

\subsubsection{CNM Perspectives}

\section{1) Leadership attributes}

The CNE role was identified as significant and essential to collaborative leadership in the clinical setting. The CNM participants articulated their understanding of this leadership role: 'I expect them to own that role ... we work side-toside and collaborate as to where we are going'. Specifically, the guidance and direction of the GRNs in the graduate programme was characterised as a leadership role: 'Leading by example ... raising the bar ... and showing the grads what the expected level is'.

The CNM participants discussed the skill set required for the role. Being the person with sound analytical skills who provided creative solutions to difficult situations was vital to good management: 'So coming up with ideas of how to manage and ... keep the ward flowing, keep everyone safe, to me is part of that leader, and they're part of that team ... they've got their education hat, but they're there also to pick up if there's issues, ideas, that we can try and problem solve together'. In the clinical context, acting as a change agent was also a highly prized skill: 'If I want something changed or implemented, then I'm going to liaise with the CNE on the best way to do it, best way to bring it in'. To have the CNE actively work as a change agent, the CNM participants recognised the need to devolve their authority: 'If they're not invested in, or had that leadership ability invested in the empowerment, then they don't come particularly credible when they're trying to deliver change'.

In role modelling professional standards, the CNEs exemplified the values, attitudes and expected clinical behaviours 
of a leadership role. Evidence of this was described by the CNM participants in relation to their own management role: 'So everybody knows ... when I'm not here ... they're the next in line'. The CNM participants acknowledged the attributes of leadership. Participants summarised the CNE qualities necessary for a favourable team outcome: 'The big thing for CNE is passion in what they do. And when that comes across, I was happy'.

\section{2) Underperformer}

With underperforming CNEs, the CNM participants identified characteristics that prevented role success. A CNM commented: 'They felt intimidated by people that were above them ... so that was really obvious. And that caused a lack of confidence in driving that role forward'. Unwillingness to take direction from the CNM was another significant issue expressed by another CNM: 'With my CNE, I have to give her a lot of direction: "This is what I want you to do"'. Another CNM described her CNE's limited understanding of the level of the education role in relation to the nurses roles: 'They just see themselves as equal, of equal standing, and they're just there to help, and it's just that they've got some knowledge and expertise that they're happy to share with their colleagues'.

The CNMs also described their concerns about the flexibility and focus of the CNE role incumbent. One CNM shared an experience: 'To me the CNE is a CNE role, now can you pull the CNE into coordinating a shift role? ... Like, I want her to concentrate on that education role, and she really struggles, because she doesn't do it all the time. She struggles with coordinating award because it's something that's unfamiliar to her. Some people can jump between those roles, and some people can't'. After having worked with a number of CNEs, another participant CNM could identify when a CNE was working in the role successfully or not meeting expectations: 'It became really obvious, and it wasn't just me dissatisfied with that but everybody else dissatisfied with that. So, you can see when it doesn't work and you can see when it works, so you've got that comparison'.

Despite the expressed issues surrounding underperforming CNEs, when difficulties arose in the ward environment, the CNM participants generally expressed their support of their CNE. Their role and active involvement and collaborative practice in ensuring staff and GRNs have access to the professional development and education requirements was necessary and significant.

\section{Discussion}

The evidence that has emerged from this study demonstrates the CNE has a congruent leadership style in the clinical ward setting. There is a level of consistency with the congruent leadership theory features and clinical leadership attributes. In the questionnaire, the GRNs specifically chose the attributes strongly and least associated with CNE clinical leadership. In comparison to Stanley's studies on congruent leadership of health professionals, ${ }^{[30-34]}$ of the top eight attributes, five were similarly ascribed to the CNE clinical leadership. These were, is approachable, supportive, clinically competent, sets direction, and has integrity and honesty. The other qualities highly valued — setting goals and targets, being a mentor and caring and compassionate-were likely chosen by the GRNs more specifically in line with the educators' role of supporting the GRNs through to successful completion of their graduate program. These qualities and characteristics are identified in the literature as significant to achieving clinical practice goals and meeting learning outcomes in the clinical environment. ${ }^{[35]}$

The attributes least associated with the CNE clinical leadership, were also reflected in Stanley's previous studies. ${ }^{[30-34]}$ These attributes were identified as not visible in the CNEs leadership. Controlling behaviour, working alone, and dealing with reward/punishment are related to poor leadership, specifically in the area of conflict management and difficult relationships. ${ }^{[36]}$ The educator role is unlikely to be perceived as an administrator, with the ward management and administration credited to their CNM. ${ }^{[37]}$ Although the attribute of 'conservative' may relate to a leader's desire for traditional methods, this was not perceived to align with the clinical environment of increasing complexity, chronicity, social care needs and advancing patient care with new technology and evidence-based practices. ${ }^{[38]}$ Similarly, the GRNs did not perceive relevance nor importance for any artistic and imaginative abilities in the CNEs leadership role. ${ }^{[39]}$ Further, by ranking relevant postgraduate training as least associated with clinical leadership, the GRNs may be limited by their own lack of understanding of the role of leadership in the clinical environment, and the benefits of enhanced evidencebased nursing care provision for the benefit of patients. ${ }^{[40]}$

The congruent leadership style is demonstrated in the clinical environment by influential nurses who do not necessarily have a formal position of leadership in the organisation. ${ }^{[41]}$ In this study the CNE was identified as a genuine 'presence' and tangible influence on the GRNs' career progression and successful transition in their graduate year and subsequent retention in the organisation. Similarly, a key finding of a qualitative study in a large NHS trust hospital identified leaders in the clinical environment as those who remained connected with patient concern and compassion as opposed to the higher-grade staff with more of a management focus and less patient interaction. ${ }^{[30]}$ A more recent Australian 
study highlighted the CNE as adding value to their clinical environment through their accessible presence, building and investing in the nursing workforce by meeting a variety of education needs. ${ }^{[42]}$ As an optimistic leader, the CNE understands the challenges of cultural change the GRNs will need to overcome to meet the expectations of the patient and organisation. ${ }^{[43]}$ In meeting the GRNs' needs at their level of confidence and learning, the CNE exhibits kindness and allays fears in order to achieve the hope, commitment, courage and collaboration necessary for long-term nurse retention. ${ }^{[44]}$ What is significant to clinical leadership is the patient-centred philosophy that connects the multifaceted challenges of the clinical environment and the nursing profession in the wider health system, and is necessary for retaining and developing future generations of nurses. ${ }^{[2]}$

Ferguson-Paré ${ }^{[45]}$ communicated a view of leadership that is lived in the frontline of care and in the presence of the nursing team members. Adelman-Mullally et al. ${ }^{[35]}$ further emphasised the CNEs' core educational role in facilitating experiences as opportunities to share their values and inspire commitment to professional and organisational goals. In the context of contemporary healthcare's financial and workforce challenges, there is a greater need for leadership that embraces values and beliefs that augment effective and efficient productivity to improve the quality of patient care. ${ }^{[46]}$

Underperforming CNEs who did not display leadership attributes, skills or mentorship, and refused or avoided the responsibility for GRNs in the role, also inhibited the GRNs' successful progress and weakened nursing team unity, resulting in reduced benefits of educational leadership assumed by the nursing team. Sayers ${ }^{[47]}$ described challenges that affect identity and confidence in the CNE role, such as ambiguity, blurring and conflict, as well as the overarching organisational culture, which leads to the absence of clinical leadership, powerlessness, personal dissatisfaction, and role stasis. The current study's findings indicated that successful CNE leaders have a compatible relationship with their CNM and demonstrate similar people skills and patient care goals. Hence, the necessity for the CNE as clinical leader to be the 'right fit' in the ward environment which is established by the acceptance of devolved responsibility and ability to work autonomously with the leadership attributes and skills that provide a consistent approach to enable the GRNs' successful progress.

Stanley ${ }^{[30]}$ suggested that a clinical leader does not need to be in a management position to lead and influence colleagues. However, in this study, the CNEs' influence was inconsistent because of displacement from their core educational duty and allocation to clinical patient care, as directed by senior hospital leadership to meet shortfalls in nurse supply and workload or financial deficits. Sayers, Salamonson, et al. ${ }^{[48]}$ discussed the competing priorities of the role, where the CNE is expected to simultaneously cover other positions, which creates frustration and stress in attempting to meet the multiple expectations of senior managers and nursing peers. Effective leadership is central to nursing ${ }^{[49]}$ thus, the CNEs' absence from the clinical environment removes the benefit of available, accessible and visible clinical leadership.

The early supporters of the CNE role suggested that effective staff development required the CNE to have a position of status in the organisation. ${ }^{[50]}$ This study recommends the CNE role be used by healthcare organisations to meet contemporary patient and healthcare expectations, uphold commitments to standards and policy, and promote GRN patient-centred practice and nurse retention in the health service. The CNEs' nursing practice, in conjunction with higher levels of qualification, is advantageous for GRN professional development and quality patient care. Postgraduate study provides sequelae related to theory to practice, such as transmission of expert knowledge and skills and application of evidence-based practice. ${ }^{[40]}$ However, the challenges to CNE role and leadership value - such as short-term staffing needs that overwhelm role value and success-need to be overcome. The CNE status should be protected and acknowledged as significant to continuing education, continuing professional development, and leadership acumen for the benefit of patient safety and the future nursing workforce. ${ }^{[51]}$ Further study on the CNE role and clinical leadership associated with patient outcomes and other nursing roles in the healthcare organisation would be beneficial for the development and delivery of healthcare policy.

\section{Limitations}

The CNE role in this study was portrayed by the GRN, $\mathrm{CNE}$ and CNM participants as a nursing leadership role that demonstrated the values necessary to support the clinical education and success of the newly qualified registered nurses. This study presents a snapshot of the CNE clinical leadership role in participating acute care hospitals in one healthcare organisation in one state of Australia. While the perceptions of the GRNs, CNEs and CNMs provided data, representation from other WA public and private health service providers may have offered a more in depth understanding of the role to compare and make recommendations. Of the three participating hospitals, one site was significantly over-represented This is likely due to the larger size of hospital being able to take more GRNs in their graduate programme. The sampling strategy provided a practical and realistic way to explore the CNE clinical leadership role. However, the GRNs and CNEs 
interview participants were all female and not wholly representative of the population. In addition, during the recruitment process, the appointment of a third party-perceived by the healthcare organisation as eliminating bias associated with the researcher's current employment in one of the hospitals-may have affected the response rate of the GRN questionnaire. The anonymous GRN questionnaire provided comment on the role and leadership of the CNE, without any unintentional yet possible power differential that may have existed in the interviews, where the GRNs may have felt they needed to give positive feedback.

\section{Conclusion}

The CNE clinical leadership is associated with the congruent leadership style and is valued by nurses at the point of care. The congruent leadership attributes underpin the ongoing clinical support which is effective and valuable in advancing the safe practice and positive patient outcomes of the GRNs' while central to their successful transition to practice and integration into the clinical setting. Despite their informal leadership role, the CNE engages and promotes the GRNs in their professional role and encourages, supports and urges the nursing profession forward and towards excellence in patient care. This study recommends that the CNE role be used by healthcare organisations as a strategically placed leader and socially adept position of importance to meet contemporary patient and healthcare expectations, uphold commitments to standards and policy, and promote GRN patient-centred practice and retention in the health service.

\section{CONFlicts OF InTEREST Disclosure}

The authors declare that there is no conflict of interest.

\section{REFERENCES}

[1] Harper J. Clinical leadership-bridging theory and practice. Nurse Educator. 1995; 20(3): 11. https://doi.org/10.1097/000062 23-199505000-00011

[2] Australian College of Nursing. Nurse Leadership. 2015. https://www.acn.edu.au/sites/default/files/leaders hip/ACN_Nurse_Leadership_White_Paper_FINAL.pdf

[3] Sayers J, DiGiacomo M, Davidson PM. The nurse educator role in the acute care setting in Australia: important but poorly described. Australian Journal of Advanced Nursing. 2011; 28(4): 44-52.

[4] Ashton KS. Nurse educators and the future of nursing. Journal of Continuing Education in Nursing. 2012; 43(3): 113-116. PMid:22263552 https://doi.org/10.3928/00220124-20120116-02

[5] Yoder-Wise PS. (Ed.). Leading and managing in nursing. 7th ed. Mosby; 2018.

[6] Dignam D, Duffield C, Stasa H, et al. Management and leadership in nursing: An australian educational perspective: Management and leadership in nursing in australia. Journal of Nursing Management. 2011; 20(1): 65-71. PMid:22229902 https://doi.org/10.111 $1 / j .1365-2834.2011 .01340 . x$

[7] Coffey JS, White BL. The clinical nurse educator role: A snapshot in time. Journal of Continuing Education in Nursing. 2019; 50(5): 228232. PMid:31026323 https://doi .org/10.3928/00220124-2 0190416-09

[8] Brennan J, Olson EL. Advancing the profession: The clinical nurse educator. Nursing. 2018; 48(10): 53-54. PMid:30256291 https: //doi.org/10.1097/01. NURSE.0000545017.83543.8f

[9] Fernandez R, Sheppard-Law S, Curtis S, et al. Exploring the experiences of neophyte nurse mentors: A qualitative study. Nurse Education in Practice. 2018; 29: 76-81. PMid:29197706 https: //doi.org/10.1016/j.nepr.2017.11.011

[10] Girard N. Educational leadership in professional nursing. Perioperative Nursing Clinics. 2009; 4: 43-49. https://doi.org/10.101 $6 / j$.cpen.2008.10.005

[11] Health Workforce Australia. Nursing workforce sustainability: Improving nurse retention and productivity. Canberra, ACT: Commonwealth of Australia. 2014.

Published by Sciedu Press
[12] Pearson MM. Transformational leadership principles and tactics for the nurse executive to shift nursing culture. JONA: The Journal of Nursing Administration. 2020; 50(3): 142-151. PMid:32068623 https://doi.org/10.1097/NNA.0000000000000858

[13] Pishgooie AH, Atashzadeh-Shoorideh F, Falcó-Pegueroles A, et al. Correlation between nursing managers' leadership styles and nurses' job stress and anticipated turnover. Journal of Nursing Management. 2019; 27(3): 527-534. PMid:30136322 https://doi.org/10.1 $111 /$ jonm. 12707

[14] Alexander C, Lopez RP. A thematic analysis of self-described authentic leadership behaviors among experienced nurse executives. JONA: The Journal of Nursing Administration. 2018; 48(1): 38-43 PMid:29219909 https://doi.org/10.1097/NNA.0000000000 000568

[15] Stanley D. Clinical leaders in paediatric nursing: a pilot study. Paediatric Nursing. 2004; 16(3): 39-42. PMid:15116685 https: //doi.org/10.7748/paed2004.04.16.3.39.c910

[16] Stanley D. (Ed.). Clinical leadership in nursing and healthcare: Values into action. 2nd ed. Wiley-Blackwell. 2017.

[17] Stanley D. Clinical leadership: Innovation into action. Palgrave MacMillan. 2011.

[18] Stanley D. Clinical leadership characteristics confirmed. Journal of Research in Nursing. 2014; 19(2): 118-128. https : //doi.org/10 $.1177 / 1744987112464630$

[19] Creswell JW. A concise introduction to mixed methods research SAGE; 2015.

[20] Yamane T. Statistics: An introductory analysis. 2nd ed. Harper and Row. 1967.

[21] Creswell JW, Creswell JD. Research design: Qualitative, quantitative, and mixed methods approaches. 5th ed. Thousand Oaks, California: SAGE Publications, Inc.; 2018.

[22] Polit DF, Beck CT. Essentials of nursing research: Appraising evidence for nursing practice. 9th ed. Wolters Kluwer Health/Lippincott, Williams \& Wilkins. 2017.

[23] Cope DG. Using electronic surveys in nursing research. Oncology Nursing Forum. 2014; 41(6): 681-682. PMid:25355023 https: //doi.org/10.1188/14.onf.681-682 
[24] Parahoo K. Nursing research: Principles, processes and issues. 3rd ed. Palgrave MacMillan. 2014.

[25] Qualtrics LLC. Qualtrics research suite. 2016. Available from: http: //www.qualtrics.com/

[26] QSR International. NVivo 10. 2014. www.qrsinternational.com

[27] Braun V, Clarke V. Successful qualitative research; a practical guide for beginners. Portland: Ringgold Inc.; 2013.

[28] National Health and Medical Research Council. National Statement on Ethical Conduct in Human Research. Canberra: National Health and Medical Research Council, the Australian Research Council and Universities, Australia. Commonwealth of Australia. Canberra. 2018.

[29] Cooper AL, Brown J. Maximising nurses' and midwives' response rates to surveys. Nurse Researcher. 2017; 25(3): 31. PMid:29251446 https://doi.org/10.7748/nr.2017.e1494

[30] Stanley D. In command of care: clinical nurse leadership explored. Journal of Research in Nursing. 2006; 11(1): 20-39. https://doi . org/10.1177/1744987106059458

[31] Cuthbertson J, Stanley D. Volunteer ambulance officers' perceptions of clinical leadership in St. John Ambulance Service WA Inc: VAO perceptions of clinical leadership. University of Western Australia, Perth Australia. 2013.

[32] Stanley D, Cuthbertson J, Latimer K. Perceptions of clinical leadership in the St John Ambulance Service in WA. Response. 2012; 39(1): 31-37.

[33] Stanley D, Hutton M, McDonald A. Western Australian allied health professionals' perceptions of clinical leadership: A research report. Bathurst, NSW: CSU Print. 2015.

[34] Stanley D, Latimer K, Atkinson J. Perceptions of clinical leadership in an aged care residential facility in Western Australia. Health Care Current Reviews. 2014; 2: 122. https://doi.org/10.4172/hc cr. 1000122

[35] Adelman-Mullally T, Mulder CK, McCarter-Spalding DE, et al. The clinical nurse educator as leader. Nurse Education in Practice. 2013; 13(1): 29. PMid:22854312 https ://doi.org/10.1016/j.nepr .2012 .07 .006

[36] Al-Sawai A. Leadership of Healthcare Professionals: Where Do we Stand? Oman Medical Journal. 2013; 28(4): 285-287. PMid:23904925 https://doi.org/10.5001/omj.2013.79

[37] Courtney M, Nash R, Thornton R, et al. Leading and managing in nursing practice: Concepts, processes and challenges. In J. Daly, S. Speedy \& D. Jackon (Eds.), Leadership \& Nursing-contemporary perspectives. 2nd ed. Elsevier. 2015. 1-20 p.

[38] Marquis BL, Huston CJ. Leadership roles and management functions in nursing: theory and application. 9th ed. Wolters Kluwer Health/Lippincott Williams and Wilkins. 2017.

[39] Potempa K, Furspan P. Leading nursing in the Academy. In J. Daly, S. Speedy \& D. Jackon (Eds.), Leadership \& Nursing - contemporary perspectives. 2nd ed. Elsevier; 2015. 239-250 p.
[40] Barnhill D, McKillop A, Aspinall C. The impact of postgraduate education on registered nurses working in acute care. Nursing praxis in New Zealand inc. 2012; 28(2): 27.

[41] Stanley D. Congruent leadership: values in action. Journal of Nursing Management. 2008; 16(5): 519-524. PMid:18558922 https : //doi.org/10.1111/j.1365-2834.2008.00895.x

[42] Thornton K. Australian hospital-based nurse educators' perceptions of their role. Journal of Continuing Education in Nursing. 2018; 49(6): 274-281. PMid:29847686 https : //doi .org/10.3928/00 220124-20180517-08

[43] Harrison HC. New graduate registerd nruse practice readiness for Australin healthcare contexts: A collective instrumental case study. (Master of Nursing Thesis). James Cook University. 2018. https : //doi.org/10.25903/5c0dbc92e6d83

[44] Spurr S, Bally J, Ferguson L. A framework for clinical teaching: A passion-centered philosophy. Nurse Education in Practice. 2010; 10(6): 349-354. PMid:20570213 https://doi.org/10.1016/j . nepr. 2010.05.002

[45] Ferguson-Paré M. Perspectives on Leadership: Moving out of the Corner of our Room. Nursing Science Quarterly. 2011; 24(4): 393396. PMid:21975491 https://doi.org/10.1177/0894318411 419214

[46] Health Workforce Australia. Leadership for the sustainability of the health system: Part 1 - A literature review. 2012. Available from: https://www.hwa.gov.au/sites/uploads/leadership-f or-sustainability-of-health-sector-literature-rev iew-012012.pdf

[47] Sayers J. The role of the nurse educator in acute care hospitals Australia (PhD thesis). Curtin University, Perth, WA. 2013. http://espace. library . curtin.edu. au: $80 / R$ ? func $=$ dbin - jump-full\&local_base=gen01-era02\&object_id=194883

[48] Sayers J, Salamonson Y, DiGiacomo M, et al. Nurse educators in Australia: High job satisfaction despite role ambiguity. Journal of Nursing Education and Practice. 2015; 5(4): 41-51. https : //doi.org/10.5430/jnep.v5n4p41

[49] Curtis EA, de Vries J, Sheerin FK. Developing leadership in nursing: Exploring core factors. British Journal of Nursing. 2011; 20(5): 306309. PMid:21471879 https://doi .org/10.12968/bjon. 2011 .20 .5 .306

[50] Tobin HM, Beeler JL. Roles and relationships of staff development educators: A critical component of impact. Journal of Nursing Staff Development. 1988; 4(3): 9196. http://ezproxy.ecu.edu.au/login?url=http: //search.ebscohost. com/login. aspx?direct=true\&d $\mathrm{b}=\mathrm{rzh} \& A N=1988083486 \&$ s ite=ehost -1 ive\&s cope $=$ site https://doi.org/10.1097/00006247-198800000-00002

[51] Clark RC, Allison-Jones L. Investing in human capital: An academicservice partnership to address the nursing shortage. Nursing Education Perspectives. 2011; 32(1): 18. PMid:21473476 https : //doi.org/10.5480/1536-5026-32.1.18 